\title{
On Non-English Major Students’ English Reading Teaching Directed by Discourse Analysis Theory
}

\author{
Kou Bingjun \\ Foreign Language School \\ North China Institute of Science and Technology \\ Yanjiao, China \\ Koubingjun2009@163.com
}

\author{
Ge Dongfeng \\ Foreign Language School \\ North China Institute of Science and Technology \\ Yanjiao, China \\ arthurgedongfeng@sohu.com
}

\begin{abstract}
Traditional English teaching has always been focused on English reading whose disadvantage is becoming more and more obvious in the improvement of modern English teaching for college students, and students need to analyze an article from a macro and overall point of view. This paper introduces the definition of discourse theory and its concrete contents, combining discourse analysis theory and English reading teaching methods, putting forwards exact operating advice on the purpose of enhancing students' consciousness of discourse analysis and improving students' reading ability.
\end{abstract}

Key words-English reading, discourse analysis, teaching of reading methods

\section{INTRODUCTION}

English learning has always been the focus of our students' study, among which the study of English reading ranks first. Traditional English reading mode emphasizes more on learning grammar and vocabulary, neglecting the cultivation of students' master of English reading skills and ability of analyzing an article systematically. Discourse analysis assists students in comprehension of the passage and improving students' reading ability.

\section{A BRIEF INTRODUCTION OF DISCOURSE ANALYSIS THEORY}

Communication is the change of information, during which discourse is the medium. That is to say, human's discourse is based on discourse, and speakers exchange information by means of context. Therefore, utterance is not only the production but also the process of communication. As a process, the discourse is the dynamic progress between two communicating parties, so discourse analysis is the use of language.

Systemic functional grammar focuses on the theories of London school in which the theories of Malinowski and Firth are the core. London school advocates analyzing language meaning from aspects of functions of language and context. In the $20^{\text {th }}$ century, on the basis of previous studies, Halliday combines the systemic grammar and functional grammar together, establishing systemic functional grammar which having exerted a great influence on modern linguistic study. According to systemic functional grammar, language is a system of choice relations, all the consequences we've got are the embodiment of choices of language. Meaning is the choice in context. Language, in relevance to meaning, is a kind of deep relation within a system. In order to express the meaning, speaker should make choices, selecting the proper choice in a selected context from various functions of language, so as to accomplish a discourse. At the same time, systemic functional grammar has also pointed out three metafunctions -ideational function, interpersonal function, and textual function, among which textual function make all constituent parts of the language relevant with each other, achieving a unified and overall meaning.

Discourse is the unit of meaning, which refers to a semantic completed spoken or written paragraph at any length. In contextual condition, discourse combines together the ideational culture, interpersonal meaning and textual meaning. Meantime, discourse can transmit culture, reflecting a certain cultural meaning.

Discourse analysis is the explanation and study of cohesion in context. Discourse analysis studies how to express a completed meaning by use of language, which usually relates to many language varieties.

What should be mentioned is that our daily life is mingled with the speaker's language communication. Even if it's an independent writing, the writer would like to imagine an language user to accomplish communication, which is also discourse practice.

\section{COLLEGE ENGLISH READING AND ITS CONTEMPORARY SITUATION}

English teaching for non-English major has its particular characteristics because of its special stage and teaching goal. According to China's current syllabus of college English teaching, college English teaching aims to cultivate students' reading ability to reach a high level, listening ability to a certain level, and primary writing and speaking ability. The basic requirement of the syllabus is that college students can manage to read the events and details of an article, and then can make analysis, inference and judgment, and comprehend the author's viewpoint and attitude. Therefore, English reaching teaching is of great importance in college English teaching, and it's the center of English teaching. The focus of teaching lies in enhancing student's reading ability, cultivating their interest in learning 
English, and developing their English sense. Reading different materials of different themes and genres can not only improve directly students' English ability, but also make sense them learn something about the relative cultural customs, broaden their horizon, cultivate good outlook on life values.

However, there exist many drawbacks in the current teaching of college English reading.

First of all, teachers have low motivation in promoting students' learning interest. Restricted by the teaching, most of China's English teaching is the traditional teacheroriented mode. Classroom is the palace where teacher talk lonely, and students don't participate and behave pessimistically. Most of the classes are boring, passive listening ones.

Secondly, English teaching has a low sense of integrity. The focus of interpretation of an article and training still lies in the level of grammar with too much emphasis on the analysis and use of words and grammatical phenomenon, abandoning the analysis of the article as a whole and appreciation of its culture. Teachers' ignorance of discourse analysis in English learning and teaching exerts a side effect on students' learning and using knowledge on discourse.

Lastly, students have mastered the reading skill separately without forming a system. The emotional analysis of the whole article has been involved in teachers' teaching process, but they usually don't have adequate time to analyze systematically, which leads to students' nonsystematical master of reading skills.

\section{TEACHING OF COLLEGE ENGLISH READING BASED ON THE DISCOURSE ANALYSIS THEORY}

English reading teaching is supposed to be improved to the discourse at a high level, with an emphasis on the training of English reading skills, avoiding the phenomenon of " looking at the tree instead of seeing the whole forest " in order to truly comprehend the article. English reading comprehension at the discourse level includes more macro understanding of the outline of text, logical relation in context, the author's thread of the article, theme of the article and the author's viewpoints and attitude, etc. Discourse analysis in college student class can be put into practice in terms of the following aspects. The paper take the text of section A of unit 2, book 4 in New Vision of College English, Harlic Haplin, for example.

\section{A. The influence of title}

As the beginning of an article, title is often made up of a word, a semantic segment or a sentence; usually neglected by teachers without a due emphasis by students. However, appeared as the first information, a title is short and pithy, and accepted by the reader as the first known information. Discourse is the process of movement from known information to unknown information, and come to realize the semantic expression finally. During reading, title is always the generalization of the central idea, signifying the genre of the article and enabling reader to imagine. Take Harlic Haplin for example, the title is a human name, which can be inferred that its main character is Harlic Haplin Take a human name as the title, the article is often a narration or biography, improving in an chronological order, which can be seen in "he was born”, "in 1913”, "in the 1920's”, "in 1942”, "Harlic Haplin died”, and "Christmas Day 1977” in the end. According to discourse analysis theory, the inference of title is practicable.

\section{$B$. The analysis of text structure}

Structure is the thread of a text, including progressive type, single-centered type, multi-viewpoint type, phenomenon-explanation type, problem-solving type. Progressive type is the progress of an article from abstraction to concretization, coming to realize the theme step by step. There are always progressive adverbs, such as what's more, further more, in addition, etc. Single-centered type is a common type, usually an argumentation. The whole passage develops based on a center, which can be seen in natural or scientific article. In this type, the main idea of the text can be inferred from title and the first paragraph according to contexts. Multi-viewpoint type is the expansion of single-centered type, usually seen in the news report. Phenomenon-explanation type and problem-solving type are the relatively specific appearance of the types mentioned above.

\section{The supplementary function of background knowledge}

English learning is a kind of cultural penetration rather than merely language learning. When learning or reading an article, one can make use of the known information as supplementary instrument in order to benefit English reading comprehension. Take Harlic Haplin for example, before learning the passage, many students are familiar with Harlic Haplin. As the famous performance artist in the world, Harlic Haplin's main work is The Gilded Age. His main form of performance artist is comedy, and his way of performance is satire, which is known information to us. All of the above can be analyzed as the potential known information, and used by reader. What should be mentioned is that the background knowledge of the reader or learner may be incorrect or inconsistent with the attitude of the author. Therefore, reader should decide the central idea subjectively according to the known background knowledge.

\section{The use of signal word}

Signal word or marked word is the key in comprehending the details of an article. Signal word symbolizes the emergence of new information, the turning point of information or the emphasis of important information. The characteristics of the common signal words are the frequency words in the article, most of which are noun, words of time or place, transitional words, causal relation words, progressive words, etc. Signal words, such as "He was born in London", "quit Britain in 1913", "at the same time”, "Hollywood”, “thus”, “in 1942”, can assist in 
understanding the article, mastering the direction, tend and speed of the article.

\section{CONCLUSION}

This paper mainly discusses the drawbacks in modern teaching of English reading, talks in detail about how to apply discourse analysis theory to the teaching of college English learning. In teaching of English reading, attention should be paid in the cultivation of students' analytical ability of discourse, establishing new knowledge structure, comprehending the meaning in macro system with the final aim to enhance the quality of English of English reading teaching and students' English level.

\section{ACKNOWLEDGMENT}

This article is sponsored by the Fundamental Research Funds for the Central Universities of China(WY1208B)

\section{REFERENCES}

[1] [1] Koda .JK; Insight into Second Language-Ways to Cross an Language; Cambridge University Press, 2007

[2] [2] Ding Yangren; Discourse Analysis; Nanjing Normal University Press, 2004

[3] [3] Liu Jinkai; Strategy in Training College English Reading; South China University of Technology Press

[4] [4] Wang Aizhi; The implication of Teaching of College English Reading from Contextual Theory

[5] Wang Junhua; A Brief Course of English Reading; Fudan University Press 